\title{
Síndrome del niño sacudido
}

\author{
Perla David G. ${ }^{1-2}$; Eugenia Cid K.1
}

\section{Shaked baby syndrome}

\begin{abstract}
An 8 month old git was odmited io hospital becouse of tonic and clonic generolized soizures, drowsiness, excilation, relinal hemorrages and sliped epyphises. She was trequently shaken by hel adolescenl unmarried mother to make her slop aying. Alrophic optic papillae were demonslualed al bolh eyes by fundoscopic examinalion and o brig frontal bilateral subdural eflusion was seen al computed oxial tornography. This late iequiered surgical drainage. At age $23 / 12$ year she has severe psicomoter retardalion and bilateral blindness Shaked baby syndrome is one of the most serious forms of battered chilo syndrome, moreover, it is hard to notice becouse its injures are frequenlly non visible
\end{abstract}

(Key words: balteted thild, child abuse, shoked bativ, subdural flusion, relinal hemorrage, epiphyses slipped.!

El maltrato infantil ha existido por siglos con diferentes grados de aceptación social. En distintos países se han definido abuso y negligencia en forma ambigua, lo que tiene origen en la percepciones diferentes del problema, provenientes de factores étnicos y culturales locales. Una definición comúnmente aceptada de negligencia o maltrato psíquico del niño es la falta deliberada en cubrir las necesidades básicas o el abandono de éste. Abuso físico es cualquier lesión no accidental provocada por un adulto a un niño, en un episodio único o recurrentc, de distinta severidad, desde leve a fatal. Abuso sexual cs cualquier actividad scxual entre un adulto y un niño, única o reitcrada.

El maltrato es una de las enfermedades más frecuentes del niño. La incidencia detectada se relaciona estrechamente con la sensibilidad do la comunidad al problema, cuya magnitud real no se conoce bien, por falta de denuncia, definiciones claras o reconocimiento de las lesiones características. En Estados Unidos de Norteamérica se cree que 10 de cada 1000 nacidos vivos sufren maltrato, el que demanda $10 \%$ de las atenciones de servicios de urgencias y es la segunda causa

1. Unidad de Neurología, Hospital Exequiel González Corićs, División Ciencias Médicas Sur, Facultad de Medicina, Uriversidad de Chilc.

2. Lnidad de Emergencia, Hospital Exequieł González Conés. de inuerte despućs del sindrome de muerte súbita infantil. La causa más frecuente de morbilidad y muertc es el traumatismo enccfalocraneano ${ }^{1,2}$.

El síndrome del niño maliatado ha sido ampliamente difundido en la literatura. Se le ha subdividido en catorce variedades, de las cuales el niño sacudido se caracteriza por su gravedad y porque puede pasar inadvertido debido a ausen. cia de lesiones traumáticas externas. Esta variedad hay que tenerla presente en niños menores de dos años, pálidos e irritables, especialmente si se encuentran sus manifestaciones más caracteristicas, que son las hemorragias retinales, lesiones oculares antiguas o alteraciones epifisiarias de huesos largos, ya que en 50 a $70 \%$ de los casos es recurrente y pucde causar parálisis cercbral, retardo mental y muerte en $35 \%$ de los alectados ${ }^{3 \cdot 6}$.

El propósito de esta presentación es ilustrar las características de las lesiones encontradas en una pacientc, con el fin de estimular cl interés por identificar el problema y así contribuir a su prevención en nuestro medio.

\section{Casn clínico}

Niña de ocho meses, producto de primera gestación, madre de 16 años, soltera. Embarazo y parto normales, peso de nacimicnto $1950 \mathrm{~g}$, apgar 9 al minuto y los 5 minutos, período de recién nacido sin morbilidad. lngress por primera vez a esa edad por vómitos y crisis tonicoclónica genera lizada. No fijaba la mirada y no seguia la luz. Había edena 
de la papila en el fondo de ojo. la ulurasonografía de cráneo, el electroencef alograma y el examen de líqujdo cefalorrsquídeo dieron resultados normales. Fue dada de alta para continuar estudiándola en neurología, pero reingres 6 sieı días despues por crisis convulsiva tonicoclónica generalizada y tendencia al sopor altemada con períodos de irritabilidad, gran palidez y abombamiento de bregma. En el fondo de ojo habían extensas hemorragias retínales y persistia edema de la papila óptica. En las radiogralías de cráneo se registraba separación marcada de las suturas, signos de hipertensión endocraneana y disyunción de las epílisis en los huesos largos de exiremidades superiores e inferiores. En la tomografía axial computadorizada se observaron signos de una importante colección subdural frontal bilateral. Por ponción del bregma se drenó $65 \mathrm{ml}$ de líquido hemorrágico y después de reiteradas punciones se observo mejoría clínica parcial, pero con niveles variables de conciencia. Por esta razón se realizó craneotomia izquierda y drenaje quirirgico del derrame subdura!, con lo que se obtuvo $200 \mathrm{ml}$ de líquido hemorrágico y nomalización de la conciencia. En controles posteriores se ha confimado atrofia óplica, con potenciales evocados visuales ausentes en ambos ojos. Actualmente liene 2 años 3 meses, sufre retraso psicomolor severo y amaurosis.

La encuesta social y la visita domiciliaria familiar identificaron a la madre como la persona causante de las lesiones de la paciente, quien sacudía en sus brazos a la niña cuando lloraba "para gue se durmiera, porque su llantu no la dejaba dormir". Posteriomente la madre abandonó cl hogar y la paciente quedó interta en una instituciŏn para este propósito, bajo custodia tegal y social, porque el restu de la familia, compuesta por abuela matema, anciana a cargo de dos líos retardados mentales, sin otros familiates, no podía hacerse cargo de ella.

\section{Comentario}

Las caracteristicas clinicas de nuestra paciente coinciden con lo descrito en la literatura. Las lesiones intracraneanas se detectan en $90 \%$ de los casos en menores de dos años, a lo que cstán predispuestos por la plasticidad, llexibilidad, vasorreactividad y mayor espacio del líquido alrededor del encéfalo. Este último, con la súbita aceleración, desaceleración y rotación a que es sometido durante las sacudidas, sufre microsangramientos repetidos que suclen expresarse en hemorragias retinianas, por las características anatómicas de la caja crancana en la región orbito-frontal y colecciones subdurales, que se producen por rotura de vasos venosos en la zona parasagital, donde son especialmente frágiles ${ }^{5,7,8}$. El derrame subdural coexiste en $70 \%$ de los casos con alteraciones $\sigma$ seas y puede ser detectado tnediante tomografía axial, aun en ausencia de manifestaciones clínicas focales, en $50 \%$ de los pacientes sospechosos y $85 \%$ de los que tienen secuelas intracraneanas. Las alteraciones óseas son características, habitualmente ocultas y múltiples, como en la descripción original de Caffey, y pueden constatarse en radiografías del esqueleto completos. Ante estos pacientes es muy importante tener un alto nivel de sospecha para conseguir el diagnóstico oportunamente, debido a la ausencia de manifestaciones extemas visibles, la gravedad de las lesiones, el riesgo de secuelas y muerte $y$ la tendencia a la repetición de los episodios de agresión. La observación debe incluir, en el niño, signos como llanto frecuente, palidez, inquictud, falta de lenguaje, otras lesiones oculares, fracturas o lesiones antiguas. Las características de los padres deben estudiarse cuidadosamente, en especial cuando hay discrepancia entre la historia del accidente y las lesiones encontradas $^{7,8}$.

Para reconocer, manejar y seguir a estos pacientes es preciso constituir equipos multidisciplinarios, ya que el abuso infantil es polisindro. mático en sus manifestaciones, variado en sus etiologías y complejo en su manejo ${ }^{9}$. El médico debe tencr presente, además, que el Código Penal chileno estipula la obligación de denunciar todo caso de lesión sospechosa de haber sido producida por terceras personas ${ }^{5}, 10$.

\section{Resumen}

Una niña de 8 meses de edad ingresó al hospital por crisis convulsivas tónico clónicas generalizadas, sopor, irritabilidad, hemorragias retinales y disyunción epifisiaria de los huesos largos. La lactante cra frecuentemente sacudida por su madre -soltera, adolescente- entre los brazos de Esta, con el objeto de silenciar su lianı. En el examen de los fondos de ojo había atrofia de ambas papilas ópticas y en la tomografía axial del cráneo se comprobó un derrame subdural frontal bilateral que obligó a drenarlo quirúrgicamentc. $A$ la edad de 2 años y 3 meses la paciente tiene retardo psicomotor severo y ceguera bilateral. El síndrome del lactantc sacudido es una de las formas mas graves de maltrato lísico infantil y es dificil de reconocer por cuanto suele no presentar manifestaciones externas de la agresión, por lo que es importante tenerlo presente.

(Palabras clave: nin̄o golpeado, abuso, lactante sacudido, dertame subdural, hemorragia retinal, disyunción epifisiaria). 


\section{Referencias}

1. Marshall $W$, Puts T, Davidson $C$ : New child abuse spectrum in an era of increased aware ness. AJDC 1988, 142: 664-667.

2. Sharma $A$, Sunderland $R$ : Increasing medical burden of child abuse. Archives of disease in childhood, 1988. 62: 172-175.

3. Sheidon $L$, Brenner $D$, Fischer $H$ : ' ' he shaken baby syndrome to the editor. J Neurosurg 1988, 68: 660 .

4. Caffley $J$ : The whiplash shaken infant syndrome: Ma. nual shaking by the extrcmities with whiplash - induced intracranial and intraocular bleedings linked with residual permanent brain damage and mental retardation. Pediatic $1974,54: 396-403$.

5. Garcia C. Zaninovic A: Síndrome del nin̄o maltratado
Hallazgos radiológicos. Rev Child Pcdiatr 1991, 62 : 273-280.

6. Purdue G, Hunt J, Prescon $P$ : Child abuse by buming $\Lambda n$ index of suspicion. The Joumal of 'Jrauma 1988, 28: $221-224$.

7. Olesen T. Egelblod M. Pelersen H. Ahlgren P. Nielsen AM, Vesierdal $J$ : Somatic manifestation in children suspected of having been maltrealed. Acla Pediatric Scand. 1988, 77: 154-160.

8. Omnaya $A_{1}$ Fass $F$, Yarnell $P$ : Whiplash Injury and brain damage. JAMA 1968, 204; 75-79.

9. Otguin E, Pinto J, Haye A, Von Bentewitz R: Sindrome del niño agredido. Actitud del pediatra en la práctica clínica. Pediatría (Santiago) 1982, 25: 127-13t.

10. Código Penal: Novena edición: Editorial Jurílica de Chile, Santiago de Chile, anticulo 194, 1984. 